\title{
Role of Neopterin, C-Reactive Protein and Myeloperoxidase in Patients Undergoing Cardiopulmonary Bypass
}

\author{
Lokman Ayaz $^{\mathrm{a}}$ Ali Unlu ${ }^{\mathrm{d}}$ Nehir Sucu ${ }^{\mathrm{b}}$ Lulufer Tamer ${ }^{\mathrm{a}}$ Ugur Atik $^{\mathrm{a}}$ \\ Mehmet Ali Sungur ${ }^{c}$ \\ ${ }^{a}$ Department of Biochemistry and Departments of ${ }^{b}$ Cardiovascular Surgery and ${ }^{c}$ Biostatistics, Mersin University \\ Faculty of Medicine, Mersin, and d Department of Biochemistry, Medical Faculty, Selcuk University, Konya, Turkey
}

\author{
Key Words \\ Neopterin $\cdot$ C-reactive protein $\cdot$ Cardiopulmonary bypass $\cdot$ \\ Myeloperoxidase $\cdot$ Cell-mediated inflammation
}

\begin{abstract}
Objective: The aim of the present study was to investigate the role of neopterin (NP), C-reactive protein (CRP) and myeloperoxidase (MPO) in patients undergoing coronary artery bypass grafting with or without cardiopulmonary bypass (CPB). Patients and Methods: Forty patients submitted for elective coronary artery bypass grafting were included in this prospective study. Patients were divided into two groups of 20 individuals, those who did not undergo CPB (group 1), aged $54.1 \pm 13.5$ years, and those who did (group 2), aged $60.2 \pm 11.7$ years. In group 1, there were 17 males and 3 females, while in group 2, there were 16 males and 4 females. Serum CRP, serum and urine NP and leukocyte MPO activity were measured preoperatively, at the end of surgery, and 4, 24 and $72 \mathrm{~h}$ after surgery using high-performance liquid chromatography, immunoturbidimetry and the reduction in o-dianizidine, respectively. Results: The level of serum NP was higher preoperatively and at the end of surgery $(0 \mathrm{~h}), 4$, 24 , and $72 \mathrm{~h}$ after the operation in those who underwent CPB compared to those who did not. However, there was no significant difference in NP concentrations between the two groups at any time except $24 \mathrm{~h}$ after surgery $(p=0.002)$. Urine
\end{abstract}

NP concentrations showed similar values preoperatively but increased postoperatively in both groups of patients. The only significant difference in urine NP concentration between the two groups occurred at 0 and $24 \mathrm{~h}$ after surgery $(p=0.001, p=0.000)$. Serum CRP concentrations showed similar values preoperatively, at the end of surgery and $72 \mathrm{~h}$ after the operation and increased at 4 and $24 \mathrm{~h}$ postoperatively in both groups. The only significant difference in CRP concentration between the two groups occurred 4 and $24 \mathrm{~h}$ after surgery ( $p=0.024$ and $p=0.000$, respectively). MPO levels were found to be increased in the CPB patients when compared to those patients who did not undergo CPB. However, the difference between the groups was not statistically significant. Conclusion: Our data show that CPB induced a rise in NP and CRP levels.

Copyright $\odot 2010$ S. Karger AG, Basel

\section{Introduction}

Cardiac surgery with cardiopulmonary bypass (CPB) induces an acute phase reaction that has been implicated in the pathogenesis of several postoperative complications [1]. A recent report [2] indicated that a complex sequence of events leads to activation of leukocytes and endothelial cells, which are responsible for cell dysfunction in different organs. Contact of blood components with

\section{KARGER \\ Fax +4161306 1234 \\ E-Mail karger@karger.ch}

www.karger.com
C) 2010 S. Karger AG, Basel

1011-7571/10/0196-0479\$26.00/0

Accessible online at:

www.karger.com/mpp
Lokman Ayaz

Mersin University, Medical Faculty

Department of Biochemistry

TR-33079 Mersin (Turkey)

Tel. +90 324337 4300, Fax +90 324337 4305, E-Mail lokmanayaz@yahoo.com 
the artificial surface of the CPB equipment leads to activation of inflammatory cells, ischemia-reperfusion injury, endotoxemia and operative trauma, which induces an inflammatory response [1]. Exposure of blood to extracorporeal artificial surfaces during CPB induces alterations in the cell-mediated immune response $[3,4]$ and a systemic inflammatory reaction, which is characterized by complement activation [4] and cytokine release such as interferon- $\gamma($ IFN- $\gamma$ ) and tumor necrosis factor- $\alpha[5,6]$.

Neopterin (NP) is produced by activated monocytes/ macrophages from guanosine triphosphate via guanosine triphosphate cyclohydrolase-1 [7]. The activity of this enzyme is greatly enhanced by IFN- $\gamma$. IFN- $\gamma$ released by activated helper $\mathrm{T}$ lymphocytes type 1 is the most potent inducer of NP production, and the concentration of NP indicates the presence of IFN- $\gamma$ in body fluids [8]. Because IFN- $\gamma$ is released by active T cells, NP may be a sensitive marker of cell-mediated immunity $[9$, 10]. NP concentration rises in the early stage of different diseases and increased levels usually correlate with the severity of the disease [11]. It has therefore been suggested that measuring NP concentration is helpful in the followup of pathological states associated with the activation of cell-mediated immunity [12].

In this study, we have investigated the role of NP and $\mathrm{C}$-reactive protein (CRP) concentration and leukocyte myeloperoxidase (MPO) activity in CPB in patients undergoing coronary artery bypass grafting (CABG) with or without $\mathrm{CPB}$.

\section{Subjects and Methods}

\section{Study Protocol}

Forty patients with stable angina pectoris who had triple vessel disease were divided into two equal groups: group 1, 20 patients (16 males and 4 females, mean age $60.15 \pm 11$ years) who underwent CABG without $\mathrm{CPB}$; group 2, 20 patients (17 males and 3 females, mean age $54.1 \pm 3.5$ years) who underwent $C A B G$ with $\mathrm{CPB}$. Exclusion criteria were patients with poor ventricular function (ejection fraction $<30 \%$ ), diabetes mellitus, renal failure and those requiring emergency surgery; exhibiting remarkably abnormal pulmonary, endocrine, metabolic, or neurological pathology that could constitute significant comorbidities; all cardiac medications were continued until the day before the surgery. After the completion of $\mathrm{CABG}$, patients were transferred to the intensive care unit (ICU). Postoperative care was standardized for all patients, and extubation was done as early as possible. Informed consent was obtained from all subjects, and the study was approved by the Ethics Committee of Mersin University, Mersin, Turkey.

\section{Surgical Procedure}

A standardized anesthetic protocol was used throughout the study. All patients received premedication with midazolam, 0.05 $\mathrm{mg} / \mathrm{kg}$ intravenously, in the operating room. The intraoperative anesthetic technique was the same for both groups. Anesthesia was induced with ethomidate $0.3 \mathrm{mg} / \mathrm{kg}$ i.v. and remifentanil 1-2 $\mu \mathrm{g} / \mathrm{kg}$ bolus followed by $0.2-0.5 \mu \mathrm{g} / \mathrm{kg} / \mathrm{min}$ infusion, and vecuronium $0.1 \mathrm{mg} / \mathrm{kg}$ i.v. was used to facilitate intubation. Anesthesia was maintained with remifentanil infusion $0.2-0.5 \mu \mathrm{g} / \mathrm{kg}$ and sevoflurane $0.5-1 \%$, both titrated according to the patient's hemodynamic response. In group 2, before the initiation of extracorporeal circulation and rewarming, 2-4 mg midazolam was given. After completion of surgery, the remifentanil infusion was stopped and a loading dose of $0.05 \mathrm{mg} / \mathrm{kg}$ morphine was given in the operating room. Propofol infusion, $1-2 \mathrm{mg} / \mathrm{kg} / \mathrm{h}$, was started in both groups once surgery was completed. CPB was established in a standardized manner, including the use of membrane oxygenator, roller pump and cardiotomy suction. The heart was exposed through a median sternotomy incision. The Octopus stabilizer (Medtronic) was used for the on-pump group. During onpump surgery, patients were cooled to $32^{\circ} \mathrm{C}$, whereas during off-pump surgery, patients were actively warmed to maintain a core temperature not lower than $35^{\circ} \mathrm{C}$. Cold blood cardioplegia was accomplished with anterograde delivery through the aortic root and retrograde delivery through the coronary sinus. A heparinization protocol of $300 \mathrm{U} / \mathrm{kg}$ for on-pump surgery and half of the given dose of heparin for off-pump surgery was followed. Protamine was used to reverse the effects of heparinization only in the on-pump group. All anastomoses were sutured by hand. In the off-pump group, intracoronary shunts were not used routinely; indications for use included poor visibility, ST segment changes, and hemodynamic instability. A standardized protocol for immediate postoperative care was followed in the adult ICU, including antiplatelet therapy (300 $\mathrm{mg}$ of aspirin $6 \mathrm{~h}$ after surgery, followed by a daily dose of $150 \mathrm{mg}$ ).

\section{Blood and Urine Sampling}

Venous blood was withdrawn into both plain tubes and also tubes containing EDTA anticoagulant. The blood and urine samples were collected preoperatively $\left(t_{0}\right)$, at the end of surgery $\left(t_{1}\right)$, and at $4 \mathrm{~h}\left(\mathrm{t}_{2}\right), 24 \mathrm{~h}\left(\mathrm{t}_{3}\right)$, and $72 \mathrm{~h}\left(\mathrm{t}_{4}\right)$ postoperatively. Serum samples were protected from light during the clotting period. They were then centrifuged and the separated serum stored at $-80^{\circ} \mathrm{C}$ until analysis of NP. Following collection, urine samples were stored frozen at $-80^{\circ} \mathrm{C}$ until analysis. EDTA-treated peripheral blood samples were freshly collected from patients for leukocyte MPO activity.

\section{Biochemical Assay}

Measurement of NP. Serum and urine NP concentrations were determined using high-performance liquid chromatography (an HP Agilent 1100 series system, München, Germany). The analytical column was a $5 \mu \mathrm{m}$ pore size Spherisorb ODS-2 $\mathrm{C}_{18}$ reverse-phase column $(4.6 \times 250 \mathrm{~mm}$; HICHROM, Waters Spherisorb, UK). The pre-column was a $\mathrm{C}_{18}$ cartridge (HICHROM). Urinary NP was determined by reverse-phase chromatography as described by Werner et al. [13]. The mobile phase was potassium phosphate buffer ( $15 \mathrm{~mm}, \mathrm{pH} 6.4)$ at a flow rate of $0.8 \mathrm{ml} / \mathrm{min}$. A sample of $10 \mu \mathrm{l}$ of untreated urine was diluted with $990 \mu \mathrm{l}$ of mobile phase containing disodium EDTA, and $20 \mu \mathrm{l}$ of this mixture was injected onto the column. Fluorometric detection was performed at an excitation wavelength of $353 \mathrm{~nm}$ and emission at $438 \mathrm{~nm}$. For the quantification of NP in serum, the same method 
was modified as described: $500 \mu \mathrm{l}$ serum and $500 \mu \mathrm{l}$ of $2 \mathrm{M}$ trichloroacetic acid were vortex mixed and centrifuged at $10,000 \mathrm{~g}$. The injection volume was $20 \mu \mathrm{l}$. NP peaks were determined according to its retention time and the peaks were confirmed by spiking with added exogenous NP (250 nM). Concentrations of NP were calculated from a prepared NP standard curve and expressed as nM. Urinary NP concentrations are related to creatinine and expressed as $\mu \mathrm{mol} \mathrm{NP} / \mathrm{mol}$ creatinine. Urinary creatinine concentrations were determined using standard routine laboratory methods on an automatic analyzer (Cobas Integra 800, Roche Diagnostic, Germany).

Measurement of CRP. Serum CRP concentrations were determined using immunoturbidimetry on a Cobas Integra 800 .

Measurement of Leukocyte MPO Activity. $2 \mathrm{ml}$ of EDTAanticoagulated whole blood was mixed with four volumes of $0.84 \%$ cold ammonium chloride. The mixture was then incubated at $4{ }^{\circ} \mathrm{C}$ for $5 \mathrm{~min}$. To eliminate all erythrocytes, the procedure was repeated 3-4 times. Following centrifugation at $1,500 \mathrm{~g}$ for $10 \mathrm{~min}$, the white cell pellet was washed and re-suspended in phosphate buffered saline (PBS) and tubes were then centrifuged at $800 \mathrm{~g}$ for $23 \mathrm{~min}$. The white cell fractions were collected and resuspended in PBS pH 7.2. Leukocyte MPO activity was determined by measuring the reduction of o-dianizidine at $410 \mathrm{~nm}$ using a spectrophotometer [14]. Whole blood count analysis was with a Sysmex XT 2000I. Results were calculated as $\mathrm{U} / \mu \mathrm{l}$ cell.

\section{Statistical Analysis}

Statistical analysis was performed with SPSS software package, version 11.5 for Windows (SPSS Inc., Chicago, Ill., USA). Categorical data were analyzed using the $\chi^{2}$ test or Fisher's exact test, where appropriate. Biochemical results were controlled for normal distribution by Shapiro-Wilks test, and according to test result all data were normally distributed. For all biochemical data, statistical analysis was performed using repeated measurements of ANOVA followed by post-hoc analysis with the Bonferroni test to detect differences between the with and without CPB groups. Results are expressed as mean \pm standard deviation (SD). A p value $<0.05$ was considered significant.

\section{Results}

The demographic features, clinical characteristics, and intraoperative data are shown in table 1 . None of the patients required re-operation or prolonged intensive care. All patients were transferred from the ICU to a hospital ward. Both length of ICU stay and total length of hospital stay are also given in table 1 .

Serum NP concentrations were increased preoperatively and at the end of surgery, 4, 24, and $72 \mathrm{~h}$ after the operation in those who underwent $\mathrm{CPB}$, compared to those who did not. There was no significant difference in NP concentrations between the two groups at any time except $24 \mathrm{~h}$ after surgery ( $\mathrm{p}=0.002$; fig. 1$)$. Urine NP concentrations also increased postoperatively in both groups

Role of Neopterin in Cardiopulmonary Bypass
Table 1. Demographic, clinical and surgical data of the study groups

\begin{tabular}{|c|c|c|c|}
\hline & $\begin{array}{l}\text { Group } 1 \\
(\mathrm{n}=20)\end{array}$ & $\begin{array}{l}\text { Group } 2 \\
(\mathrm{n}=20)\end{array}$ & $\begin{array}{l}\mathrm{p} \\
\text { value }\end{array}$ \\
\hline Age, years & $54.1 \pm 13.54$ & $60.15 \pm 11.7$ & 0.053 \\
\hline Males/females & $17 / 3$ & $16 / 4$ & 0.120 \\
\hline \multicolumn{4}{|l|}{ BMI } \\
\hline$\leq 25$ & $13(65 \%)$ & $14(70 \%)$ & \\
\hline$\geq 25$ & $7(35 \%)$ & $6(30 \%)$ & \\
\hline \multicolumn{4}{|l|}{ Preoperative treatment } \\
\hline Digoxin & 4 & 2 & \\
\hline Diuretic & 3 & 2 & \\
\hline Nitrate & 11 & 9 & \\
\hline Calcium channel blockers & 5 & 4 & \\
\hline Beta-blockers & 6 & 5 & \\
\hline $\mathrm{CPB}$ duration, $\min$ & - & $112 \pm 16$ & \\
\hline \multicolumn{4}{|l|}{ Duration of aortic } \\
\hline cross-clamping, min & - & $35 \pm 4$ & \\
\hline Lowest temperature, ${ }^{\circ} \mathrm{C}$ & $28.0 \pm 0$ & $28.0 \pm 0$ & 0.912 \\
\hline Hematocrit before induction & $0.42 \pm 0.3$ & $0.43 \pm 0.4$ & 0.714 \\
\hline Min. hematocrit during $\mathrm{CPB}$ & - & $0.27 \pm 0.3$ & \\
\hline ICU LOS, median (range), days & $2(1-6)$ & $2(1-7)$ & 0.651 \\
\hline \multicolumn{4}{|l|}{ Total hospital stay, } \\
\hline median (range), days & $5(2-10)$ & $5(2-12)$ & 0.474 \\
\hline \multicolumn{4}{|l|}{ Surgical data } \\
\hline Saphenous vein grafts & $2.4 \pm 0.4$ & $2.5 \pm 0.3$ & 0.816 \\
\hline Internal mammary artery & 16 & 17 & \\
\hline Inotropic support after CPB & 4 & 3 & \\
\hline
\end{tabular}

$\mathrm{BMI}=$ Body mass index; LOS $=$ length of stay; NS = nonsignificant.

of patients, with the highest concentrations occurring between 0 and $24 \mathrm{~h}$ after surgery, then declined to values approaching those observed before surgery and at $72 \mathrm{~h}$. The only significant difference in urine NP concentrations between the patients in the two groups occurred at 0 and $24 \mathrm{~h}$ after surgery $(\mathrm{p}=0.001, \mathrm{p}=0.000$, respectively; fig. 2). MPO activities reached their maximum levels at the end of surgery in both groups and declined thereafter to preoperative values $72 \mathrm{~h}$ after surgery. There was no significant difference between MPO activities in the patients in the two groups at any time (fig. 3). Serum CRP concentrations started to increase at $4 \mathrm{~h}$ postoperatively, and reached maximum concentration $24 \mathrm{~h}$ postoperatively in both groups. CRP concentrations were significantly higher in patients in group 2 than in those in group 1 at 4 and $24 \mathrm{~h}$ after operation; significantly higher CRP levels were observed postoperatively at 4 and $24 \mathrm{~h}$ in the $\mathrm{CPB}$ patient group $(\mathrm{p}=0.024$ and $\mathrm{p}=0.001$, respectively; fig. 4). 


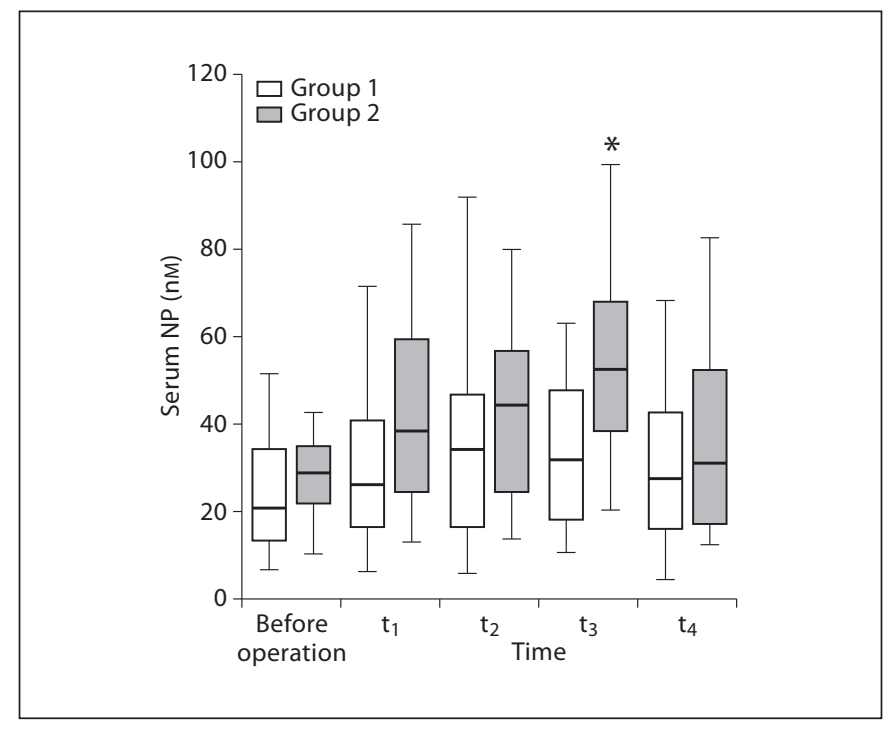

Fig. 1. Serum NP values during the operative and postoperative periods. $t_{1}=$ At the end of surgery; $t_{2}=4 \mathrm{~h}$ after surgery; $t_{3}=24 \mathrm{~h}$ after surgery; $t_{4}=72 \mathrm{~h}$ after surgery. Values are given as mean \pm SD. Group 1: without CPB; group 2: with CBP. ${ }^{*} \mathrm{p}=0.002$.

\section{Discussion}

It has been known for several years that $\mathrm{CPB}$ is associated with a generalized inflammatory response [3]. The exposure of blood cells and plasma to artificial membranes and the activation of several cell types in the setting of ischemia and reperfusion are believed to play an important role in the development of this generalized inflammatory reaction [15]. Endotoxin and various mediators have been reported to be involved in CPB-induced reactions, which can lead to postoperative organ dysfunction [16]. It is generally accepted that many proand anti-inflammatory mediators may become predominant and lead to a deficiency of immunological function during and after CPB $[16,17]$. Soluble adhesion molecules released into the circulation are believed to be markers of cellular activation and reflect the extent of inflammation and endothelial damage [18]. Some studies have measured cell-mediated inflammation during the surgery in order to determine its association with systematic inflammatory response syndrome (SIRS). Some have measured adhesion molecules such as CD11a/ CD18, CD11b/CD18, integrin and L-selectin. Using flow cytometry, they have shown that either CD11a/CD18 or $\mathrm{CD} 11 \mathrm{~b} / \mathrm{CD} 18$ surface antigen concentrations are increased during and/or after $\mathrm{CPB}$ surgery. It has also been proposed that filtering the circulatory macro-

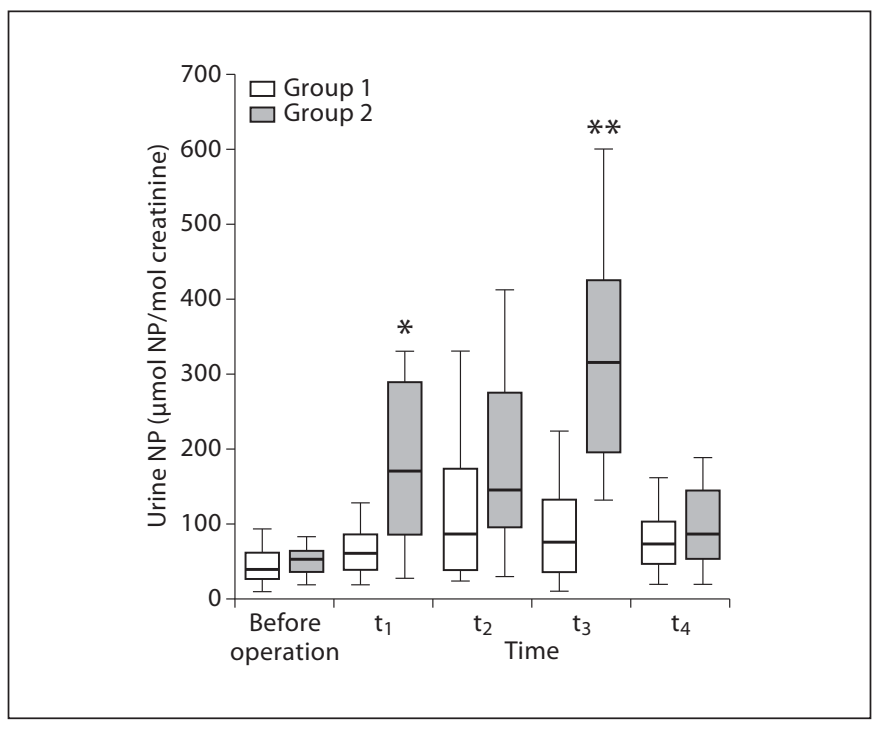

Fig. 2. Urine NP values during the operative and postoperative periods. Values are given as mean \pm SD. ${ }^{*} \mathrm{p}=0.001 ;{ }^{* *} \mathrm{p}=0.000$.

phages may reduce the oxidative burst during the $\mathrm{CPB}$ [19-21].

Our results showed that serum NP concentrations increased in both groups of patients postoperatively, reached a plateau and then decreased by $72 \mathrm{~h}$ after surgery. Concentrations were only significantly different between the two groups at $24 \mathrm{~h}$ after surgery, similar to those reported by Johansson-Synnergren et al. [22] and Brkic et al. [23] but not to Hensel et al. [24], who reported that there was no significant difference in serum NP concentrations between the groups which were without SIRS, SIRS with acute lung injury and SIRS with acute lung injury in $\mathrm{CPB}$ patients, $4 \mathrm{~h}$ after operation. In this study, the insignificance of results can be explained by the small number of patients. We believe this is the first report measuring urine NP concentrations in patients undergoing $\mathrm{CABG}$ with or without $\mathrm{CPB}$. We found that urine NP concentrations were higher in those patients that had undergone CPB than in those who had not, but the difference was only significant at the end of surgery and $24 \mathrm{~h}$ after surgery.

NP is produced by activated monocytes/macrophages from guanosine triphosphate via guanosine triphosphate cyclohydrolase-1 [7]. The activity of this enzyme is greatly enhanced by IFN- $\gamma$. IFN- $\gamma$ released by activated T lymphocytes type 1 is the most potent inducer of NP production, and the concentration of NP indicates the presence 


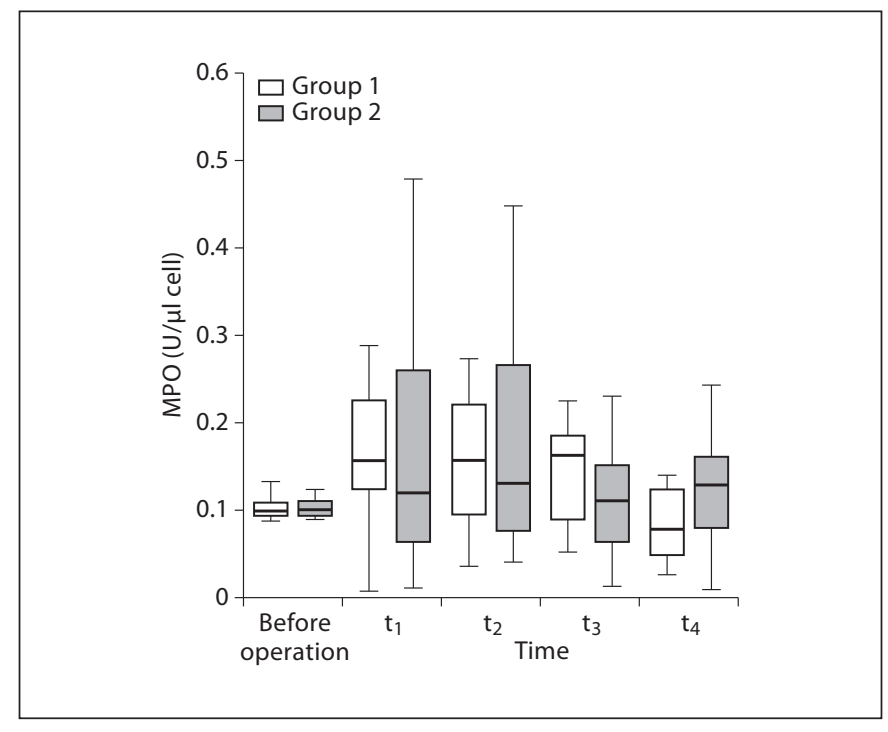

Fig. 3. MPO values during the operative and postoperative periods. Values are given as mean \pm SD.

of IFN- $\gamma$ in body fluids [8]. Because IFN- $\gamma$ is released by active T cells, NP may be a sensitive marker of cell-mediated immunity $[8,9]$. NP concentrations rise in the early stage of different diseases and increased levels usually correlate with the severity of the disease [11]. Therefore, measuring NP levels is helpful for follow-up of pathological states associated with the activation of cell-mediated immunity [12]. The increase in NP concentrations observed postoperatively in the on-pump group could represent a cumulative consequence of blood being in contact with the tubing associated with the $\mathrm{CPB}$ equipment and subsequent activation of monocytes/macrophages [16, 25].

Measurements of NP in serum by HPLC is flawed by the fact that the reduced NP derivative, 7.8-dyhydroneopterin, undergoes oxidation to NP in acidic solution and the presence of air oxygen $[13,26]$. This fact may explain why the urine NP concentrations are in accord with data in the literature [27] (in this case no acidification is necessary/performed), whereas the serum concentrations are approximately twice as high compared with literature data on the basis of immunoassays.

In the present study, CRP concentrations did not change during surgery in either group of patients. However, concentrations started to rise $4 \mathrm{~h}$ postoperatively, reaching a peak at $24 \mathrm{~h}$, before decreasing at $72 \mathrm{~h}$. Concentrations were significantly higher in group 2 patients at 4 and $24 \mathrm{~h}$ after surgery, similar to a previous report [28], in

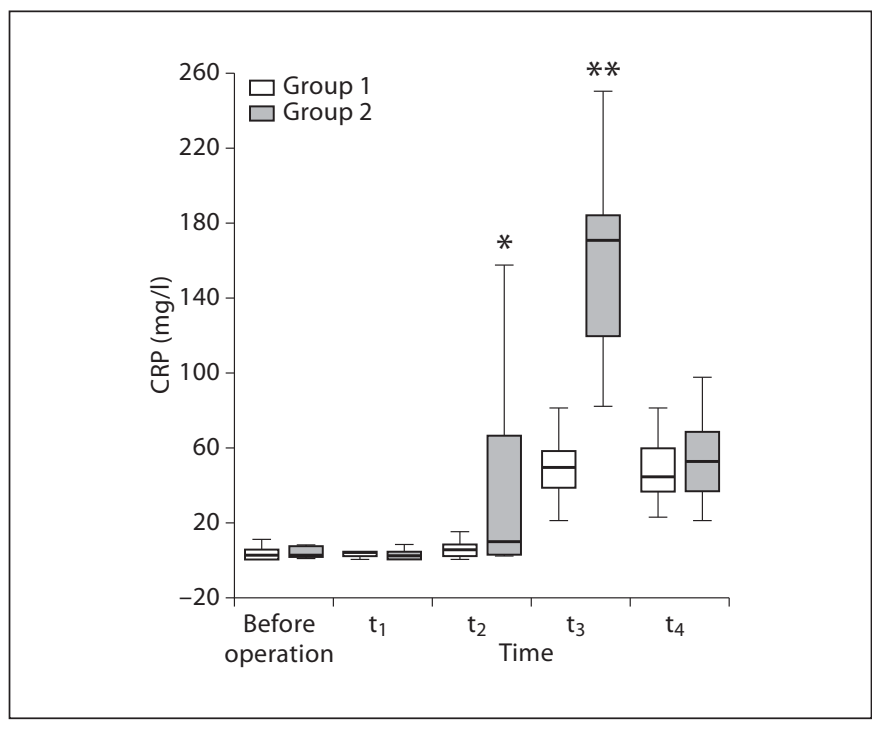

Fig. 4. CRP values during the operative and postoperative periods. Values are given as mean \pm SD. ${ }^{*} \mathrm{p}=0.024 ;{ }^{* *} \mathrm{p}=0.000$.

which CRP concentrations were observed $4 \mathrm{~h}$ after operation in both groups. However, $24 \mathrm{~h}$ after surgery the increase in CRP in the CPB group was significantly greater than in the non-CPB group. In contrast, in another study, only non-significant increases in CRP concentration were observed after surgery [25]. MPO is a specific marker of primary neutrophil granules that are released in response to strong stimuli, and high activities of MPO at the end of $\mathrm{CPB}$ indicate a profound activation of neutrophils.

In the present study, MPO activities peaked at 0 and $4 \mathrm{~h}$ after surgery before decreasing to presurgery values at $72 \mathrm{~h}$. MPO activities were higher in the patients who had undergone $\mathrm{CPB}$, but there was no difference in MPO levels among the groups at any time points in this study.

Kutay et al. [29] showed that heparin-coated CPB circuits exhibit a favorable effect on MPO reduction. Studies have shown that heparin possesses anti-inflammation and anti-oxidation properties [30, 31]. In our study, all patients, including the control group, received heparin as an anticoagulant during the surgery. No difference in MPO levels between groups in this study can be explained by the anti-inflammatory and anti-oxidative properties of heparin that is used during surgery.

In this study, those patients who underwent surgery with $\mathrm{CPB}$ demonstrated an increased inflammatory response compared to those who did not. This was reflected by the observed increases seen in both CRP and NP. 


\section{Conclusion}

Because urine NP levels were increased postoperatively at $0 \mathrm{~h}$, urine NP may be a marker for early response in $\mathrm{CPB}$; accordingly, we suggest that NP concentration in serum and urine could be used as a marker of inflammation in patients undergoing $\mathrm{CPB}$.

\section{Acknowledgements}

This work was supported by the Mersin University Research Projects Department (BAP SBE BK (LA) 2003-2 YL).

\section{References}

1 Paparella D, Yau TM, Young E: Cardiopulmonary bypass induced inflammation pathophysiology and treatment. An update. Eur J Cardiothorac Surg 2002;21:232-244.

-2 Gu JY, Mariani MA, Boonstra PW, Grandjean JG, van Overen W: Complement activation in coronary artery bypass grafting patients without cardiopulmonary bypass Chest 1999;116:892-898.

3 Butler J, Rocker GM, Westaby S: Inflammatory response to cardiopulmonary bypass. Ann Thorac Surg 1993;55:552-559.

-4 Kirklin JK, Westaby S, Blacksone EH, Kirklin JW, Chenoweth DE, Pacifico AD: Complement and the damaging effects of cardiopulmonary bypass. J Thorac Cardiovasc Surg 1983;86:845-857.

5 Kestin AS, Valeri CR, Khuri SF, Loscalzo J, Ellis PA, MacGregor H, Birjiniuk V, Ouimet H, Pasche B, Nelson MJ: The platelet function defect of cardiopulmonary bypass. Blood 1993;82:107-117.

-6 Sellke FW, Boyle EM Jr, Verrier ED: Endothelial cell injury in cardiovascular surgery: the pathophysiology of vasomotor dysfunction. Ann Thorac Surg 1996;62:1222-1228.

-7 Jerin A, Pozar-Lukanovic N, Sojar V, Stanisavljevic D, Paver-Erzen V, Osredkar J: Neopterin - an early marker of surgical stress and hypoxic reperfusion damage during liver surgery. Clin Chem Lab Med 2002;40:663666.

$>_{8}$ Huber C, Batchelor JR, Fuchs D, Hausen A, Lang A, Niederwieser D, Reibnegger G, Swetly P, Troppmair J, Wachter H: Immune response-associated production of neopterin. Release from macrophages primarily under control of interferon-gamma. J Exp Med 1984;160:310-316.

>9 Vrecko K, Staedtler P, Mischak I, Maresch L, Reibnegger G: Periodontitis and concentrations of the cellular immune activation marker neopterin in salvia and urine. Clin Chim Acta 1997;268:31-40.

10 Müller TF, Vogl M, Neumann MC, Lange H, Grimm M, Müller MM: Noninvasive monitoring using serum amyloid $\mathrm{A}$ and serum neopterin in cardiac transplantation. Clin Chim Acta 1998;276:63-74.

11 Berdowska A, Zwirska-Korczala K: Neopterin measurement in clinical diagnosis. J Clin Pharm Ther 2001;26:319-329.
12 Fuchs D, Hausen A, Reibnegger G, Werner ER, Dierich MP, Wachter H: Neopterin as a marker for activated cell-mediated immunity: application in HIV infection. Immunol Today 1988;9:150-155.

13 Werner ER, Bichler A, Daxenbichler G, Fuchs D, Fuith LC, Hausen A, Hetzel H, Reibnegger G, Wachter H: Determination of neopterin in serum and urine. Clin Chem 1987;33:62-66.

14 Golowich SP, Kaplan SD: Methods in Enzymology. New York, Academic Press, 1955, vol 2, p 769

15 Verrier ED, Boyle EM Jr: Endothelial cell injury in cardiovascular surgery. Ann Thorac Surg 1996;62:915-922.

16 Hall RI, Smith MS, Rocker G: The systemic inflammatory response to cardiopulmonary bypass: pathophysiological, therapeutic, and pharmacological considerations. Anesth Analg 1997;85:66-82.

17 Menasche P: The inflammatory response to cardiopulmonary bypass and its impact on postoperative myocardial function. Curr Opin Cardiol 1995;10:597-604.

18 Boldt J, Osmer C, Linke LC, Dapper F, Hempelmann G: Circulating adhesion molecules in pediatric cardiac surgery. Anesth Analg 1995;81:1129-1135.

19 Toft P, Tonnesen E, Zülow I, Nielsen CH, Hokland M: Expression of adhesion and activation molecules on lymphocytes during open-heart surgery with cardiopulmonary bypass. Scand Cardiovasc J 1997;31:91-95.

20 Asimakopoulos G, Kohn A, Stefanou DC, Haskard DO, Landis RC, Taylor KM: Leukocyte integrin expression in patients undergoing cardiopulmonary bypass. Ann Thorac Surg 2000;69:1192-1197.

21 Tárnok A, Bocsi J, Rössler H, Schlykow V, Schneider P, Hambsch J: Low degree of activation of circulating neutrophils determined by flow cytometry during cardiac surgery with cardiopulmonary bypass. Cytometry 2001;46:41-49.

22 Johansson-Synnergren M, Nilsson F, Bengtsson A, Jeppsson A: Off-pump CABG reduces complement activation but does not significantly affect peripheral endothelial function: a prospective randomized study. Scand Cardiovasc J 2004;38:53-58.
23 Brkic K, Unic D, Sutlic Z, Biocina B, Rudez I, Baric D, Lukic IK: Neopterin kinetics after cardiac surgery with or without cardiopulmonary bypass. Coll Antropol 2006;30:395400.

24 Hensel M, Volk T, Docke WD, Kern F, Tschirna D, Egerer K, Konertz W, Kox WJ: Hyperprocalcitonemia in patients with noninfectious SIRS and pulmonary dysfunction associated with cardiopulmonary bypass. Anesthesiology 1998;89:93-104.

25 Bruins P, te Velthuis H, Yazdanbakhsh AP, Jansen PG, van Hardevelt FW, de Beaumont EM, Wildevuur CR, Eijsman L, Trouwborst A, Hack CE: Activation of the complement system during and after cardiopulmonary bypass surgery: postsurgery activation involves $C$-reactive protein and is associated with postoperative arrhythmia. Circulation 1997;96:35-42.

26 Flavall EA, Crone EM, Moore GA, Gieseg SP: Dissociation of neopterin and 7,8-dihydroneopterin from plasma components before HPLC analysis. J Chromatogr B Analyt Technol Biomed Life Sci 2008;15:167-171.

27 Altındag ZZ, Sahin G, Inanici F: Urinary neopterin excretion and dihydropteridine reductase activity in rheumatoid arthritis. Rheumatol Int 1998;18:107-111.

28 Rastan AJ, Bittner HB, Gummert JF, Walther T, Schewick CV, Girdauskas E, Mohr FW: On-pump beating hearts versus off-pump coronary artery bypass surgery-evidence of pump-induced myocardial injury. Eur J Cardiothorac Surg 2005;27:1057-1064.

29 Kutay V, Noyan T, Ozcan S: Biocompatibility of heparin-coated cardiopulmonary bypass circuits in coronary patients with left ventricular dysfunction is superior to PMEAcoated circuits. J Card Surg 2006;21:572-577.

30 Paparella D, Al Radi OO, Meng QH: The effects of high-dose heparin on inflammatory and coagulation parameters following cardiopulmonary bypass. Blood Coagul Fibrinolysis 2005; 16:323-328.

- 31 Berg K, Haaverstad R, Astudillo R: Oxidative stress during coronary artery bypass operations: importance of surgical trauma and drug treatment. Scand Cardiovasc J 2006; 40:291-297. 